\title{
ĐÁNH GIÁ GIÁ TRI SINH THIẾT DƯớI HƯỚNG DẪN SIÊU ÂM QUA TRỰC TRÀNG TRONG CHẨN ĐOÁN UNG THƯ TUYẾN TIỀN LIÊTT
}

\section{TÓM TẮT}

Nghiên cứu trên 84 bệnh nhân được sinh thiết tuyến tiền liêt qua siêu âm trực tràng tại phòng siêu âm khoa chẩn đoán hình ảnh bệnh viện $\mathrm{K}$ từ tháng 12/2017 - 6/2020.Tuổi trung bình của nhóm BN nghiên cứu là 72,1 tuổi. Đa số bệnh nhân đến khám bệnh vì tiểu khó, bí tiểu (92,8\%). 22,6\% bệnh nhân phải đặt sonde niệu đạo hoặc dẫn lưu bàng quang vì bí tiểu. Tì lệ phát hiện dấu hiệu nghi ngờ ung thư qua thăm khám lâm sàng, siêu âm qua thành bụng và siêu âm qua trực tràng lần lượt là $44 \%, 27,3 \%$ và $41,6 \%$. Các bệnh nhân chủ yếu được sinh thiết bằng phương pháp 10 mẫu (73,8\%). Độ nhạy 93,8\%, độ đặc hiệu 82,8\%. Giá trị dự đoán dương tính là $88.4 \%$, giá trị dự đoán âm tính $90.6 \%$. Biến chứng sau sinh thiết: chảy máu hâu môn $(17,8 \%)$ và tiểu máu $(14,2 \%)$, 1 bênh nhân viêm tâng sinh môn. Các biến chứng đều ở mức độ nhe, tư khỏi sau điều trị nội khoa. Tóm lai, sinh thiết tuyến tiền liệt dưới hướng dẫn của siêu ẩm qua trực tràng là một thủ thuật an toàn và có độ chính xác cao.

Tư khóa: ung thư tuyến tiền liệt, sinh thiết, siêu âm qua trực tràng.

\section{SUMMARY}

EVALUATION THE ACCURACY OF TRANSRECTAL ULTRASOUND GUIDED BIOPSY IN DIAGNOSING PROSTATE CANCER

Study of 84 patients undergone transrectal ultrasound guided prostate at radiology department of National Cancer Hospital between December 2017 and June 2020.Mean age was 72.1. The main presenting reasonsymptomwas urinary retention (92.8\%). $22.6 \%$ of all patients required catheterisation (an indwelling urethral catheter or a suprapubic catheter). The rate of suspicious symptoms of prostate cancer diagnosed by clinical examination, abdominal ultrasound and transrectal ultrasound were $44 \%, 27.3 \%$ and $41.6 \%$ respectively. Most patients had 10 samples (73.8\%). Sensitivity and specificity were $93.8 \%$ and $82.8 \%$, respectively. The positive predicted value and negative predicted value were $88.4 \%$ and $90.6 \%$, respectively. After biopsy, $17,8 \%$ of all patients had rectal bleeding, followed by hematuria (14.2\%); one patient got perineal inflammation. All of these complications were mild and recoveredsoon after procedure.To sum up, Transrectal ultrasound guided biopsy in diagnosing prostate cancer was safe and had high accuracy.

${ }^{1}$ Trường Đại học Y Hà Nội

${ }^{2}$ Bênh viên $K$

Chịu trách nhiệm chính: Trịnh Lê Huy

Email: trinhlehuy@hmu.edu.vn

Ngày nhận bài: 7.6.2021

Ngày phản biên khoa họ: 29.7.2021

Ngày duyệt bài: 10.8.2021
Trịnh Lê Huy ${ }^{1}$, Lê Việt ${ }^{2}$

Keywords: Prostate cancer, Transrectal ultrasound guided biopsy

\section{I. ĐẶT VẤN ĐỀ}

Theo thống kê của GLOBOCAN 2020, ung thư tuyến tiền liệt (UTTTL) đứng hàng đầu trong các ung thư hệ tiết niệu và đứng thứ hai trong các bệnh ung thư ở nam giớichỉ sau ung thư phổi với tỷ lê mới mắc và tử vong tính chung trên toàn thế giới là $30,7 / 100000$ và $7,7 / 100000$ nam giới ${ }^{1}$.Tại Việt Nam, UTTTL cũng đứng hàng đầu trong các ung thư đường tiết niệu và đứng thứ năm trong các bệnh ung thư ở nam giới với tỉ lệ mới mắc là $12,2 / 100000$ nam giới ${ }^{1}$. UTTTL thường diễn biến chậm trong nhiều năm và khi biểu hiện triệu chứng lâm sàng là đã ở giai đoạn muộn. Trên thực tế, tỷ lệ chẩn đoán bệnh ở giai đoạn sớm chưa được $\mathrm{cao}^{2}$. Chẩn đoán xác định cần dựa vào thăm trực tràng, định lượng PSA huyết thanh và kết quả sinh thiết tuyến tiền liệt (STTTL), trong đó kết quả sinh thiết là chẩn đoán quyết định. Tuy nhiên kết quả sinh thiết phụ thuộc nhiều vào phương pháp và kỹ thuât sinh thiết ${ }^{3}$. Ở bệnh viện $K$, phương pháp sinh thiết tuyến tiền liệt dưới hướng dẫn của siêu âm qua trực tràng đước áp dungvà đóng vai trò rất quan trọng trong chẩn đoán bệnh UTTTL. Tuy nhiên, chưa có nghiên cứu nào từ các bác sĩ lâm sàng nhằm đánh giá hệ thống các đặc điểm lâm sàng, cân lâm sàng và đánh giá vai trò của phương pháp sinh thiết tuyến tiền liệt dưới hướng dẫn siêu âm qua trực tràng. Do đó chúng tôi thực hiện nghiên cứu này với mục tiêu: "Đánh giá giá trị của sinh thiết dưới hướng dẫn siêu âm qua trực tràng trong chẩn đoán ung thư tuyến tièn liệt".

\section{II. ĐỐI TƯợNG VÀ PHƯƠNG PHÁP NGHIÊN CỨU}

2.1. Thời gian và địa điểm. Gồm 84 bệnh nhân (BN) đến khám và điều trị tạibệnh viện $K$ được sinh thiết tai phòng siêu âm khoa chẩn đoán hình ảnh từ tháng 12/2017 - tháng 6/2020.

\section{2. Đối tượng nghiên cứu}

2.2.1. Tiêu chuẩn lựa chọ:

- Những bệnh nhân được chỉ định sinh thiết dựa trên một trong ba tiêu chí sau:

o Lâm sàng: Thăm trực tràng phát hiện tuyến tiền liêt có nhân cứng/ khối chắc.

- Cận lâm sàng: nồng độ PSA toàn phần máu $>10 \mathrm{ng} / \mathrm{ml}$.

o PSA toàn phần trong khoảng $4-10 \mathrm{ng} / \mathrm{ml}$ và 
có hình ảnh siêu âm nghi ngờ UTTTL.

- Tất cả các bệnh nhân sau sinh thiết đều được phẫu thuật (cắt một phần hoặc toàn bộ tuyến) để có GPB sau mổ đối chiếu.

- Có đầy đủ thông tin lưu trữ trong hồ sơ bệnh án

\subsubsection{Tiêu chuẩn loại trừ:}

- Các bệnh nhân không có hồ sơ bệnh án đầy đủ.

- Các bênh nhân có chống chỉ định sinh thiết tuyến tiền liệt: Rối loạn đông máu, đang điều trị thuốc chống đông, nhiễm khuẩn tầng sinh môn, bệnh nhân nhiễm khuẩn tiết niệu nặng, bệnh lý suy giảm miễn dich,...

2.3. Cỡ mẫu: lấy mẫu thuận tiện

2.4. Phương pháp nghiên cứu: Nghiên cứu mô tả hồi cứu

\subsection{Cách thức tiến hành}

- Thu thập hồ sơ bệnh án theo mẫu bệnh án

- Chọn bệnh nhân đủ tiêu chuẩn vào nghiên cứu

- Thu thập các biến số nghiên cứu, bao gồm:

o Đặc điểm lâm sàng: tuổi, lí do vào viện (bí tiểu, hội chứng kích thích...)

o Đặc điểm cận lâm sàng: siêu âm ổ bụng, siêu âm qua trực tràng, nồng độ PSA

○ Số mẫu sinh thiết được: 10 mẫu, 6-9 mẫu, $<6$ mẫu

○ Giá trị của phương pháp: độ nhạy, độ đặc hiệu, giá trị dự đoán dương tính, giá trị dự đoán âm tính

o Biến chứng trong và sau thủ thuật: chảy máu qua hậu môn, đái máu, nhiễm khuẩn.

\subsection{Phân tích số liêu:}

- Thu thập các số liệu dựa trên mẫu bệnh án nghiên cứu.

- Số liệu nghiên cứu được mã hoá, nhập, xử lý và phân tích trên máy tính, sử dụng phần mềm SPSS 16.0 .

\section{7. Đạo đức nghiên cứu:}

- Việc tiển hành nghiên cứu có xin phép và được sự đồng ý của lãnh đạo Bệnh viện $\mathrm{K}$.

- Thông tin về tình trạng bệnh và thông tin cá nhân khác của bệnh nhân được giữ bí mật.

- Các thông tin thu được của đối tượng chì nhằm mục đích nghiên cứu

\section{KẾT QUẢ NGHIÊN CỨU}

\section{1. Đặc điểm lâm sàng, cận lâm sàng}

Các đặc điểm lâm sàng, cận lâm sàng được thể hiện trong Bảng 1 và Bảng 2. Tuổi trung bình của các $\mathrm{BN}$ trong nghiên cứu là $72.1 \pm 8.7$. BN ít tuổi nhất là 41 tuổi, BN cao tuổi nhất là 88 tuổi. BN đến khám hầu hết là do rối loan tiểu tiên kiểu tắc nghẽn (92,8\%)và hội chứng kích thích ở các mức độ khác nhau (36,9\%). Có 19 BN bí tiểu cấp tính phải dẫn lưu bàng quang hoặc đă̆t sonde niệu đạo (22,6\%). Các triệu chứng khác như tiểu máu, tiểu mủ gặp ở lần lượt $15,4 \%$ và $7,1 \%$ các trường hợp. Không có bệnh nhân nào có triệu chứng của giai đoan di căn xa.

Bảng 1: Phân bốđộ tuổi nghiên cútu (n= 84):

\begin{tabular}{|c|c|c|c|}
\hline Tuối & ST (+) & ST (-) & Tống \\
\hline$<60$ & 6 & 4 & 10 \\
\hline $60-69$ & 12 & 8 & 20 \\
\hline $70-79$ & 26 & 17 & 43 \\
\hline$\geq 80$ & 8 & 3 & 11 \\
\hline Tống & 52 & 32 & 84 \\
\hline Trung bình & 72,4 & 71,7 & 72,1 \\
\hline \multicolumn{4}{|c|}{$\mathrm{p}>0,05$} \\
\hline
\end{tabular}

Bảng 2: Các triệu chứng lâm sàng

\begin{tabular}{|c|c|c|}
\hline Triệu chứng & Tổng & Tỷ lệ (\%) \\
\hline Tiểu khó, bí tiểu & 78 & 92,8 \\
\hline Tiếu rắt, tiếu đêm & 31 & 36,9 \\
\hline $\begin{array}{c}\text { Cần dần lưu bàng } \\
\text { quang/ đă̆t sonde tiểu }\end{array}$ & 19 & 22,6 \\
\hline Tiếu máu & 13 & 15,4 \\
\hline Tiếu buốt, tiếu đục & 6 & 7,1 \\
\hline Cầu bàng quang & 4 & 4,7 \\
\hline Lý do khác & 3 & 3,5 \\
\hline
\end{tabular}

Tỉ lệ phát hiện dấu hiệu nghi ngờ ung thư qua thăm khám lâm sàng, siêu âm qua thành bụng và siêu âm qua trực tràng lần lượt là $44 \%$, $27,3 \%$ và $41,6 \%$. Tất cả các bệnh nhân có nồng độ PSA $\geq 4$, trong đó có $39,2 \%$ số bệnh nhân có nồng độ PSA > 100ng/ml.

3.2. Kết quả sinh thiết. Chúng tôi thực hiện sinh thiết 10 mẫu quy chuẩn, nhưng sẽ ưu tiển lấy những điểm nghi ngờ ung thư trên siêu âm trực tràng trước với những trường hợp $\mathrm{BN}$ có nguy cơ chảy máu, đau nhiều trong sinh thiết... và dừng sinh thiết để đảm bảo an toàn cho $\mathrm{BN}$ nếu cần. Trong $84 \mathrm{BN}$ tham gia nghiên cứu, có $60 \mathrm{BN}$ sinh thiết lấy được 10 mẫu $(71.4 \%), 14$ BN được sinh thiết từ 6-9 mẫu $(16.7 \%)$ và chỉ có 10 BN sinh thiết được dưới 6 mấu (11.9\%).

Có 52 bệnh nhân có kết quả sinh thiết dương tính, trong đó kết quả giải phẫu bệnh sau mổ dương tính ở 46 trường hợp, 6 bệnh nhân còn lại có kết quả giải phẫu bệnh sau mổ là lành tính, tuy nhiên $5 / 6$ trường hợp này đều có kết quả sinh thiết không đề cập đến điểm Glaeson. Trong 32 bệnh nhân có kết quả sinh thiết âm tính, có 29 BN được chẩn đoán là u phì đại tiền liệt tuyến. Đáng chú ý có 3 BN sau mổ kết quả giải phẫu bệnh là UTTTL mà trước đó có kết quả sinh thiết âm tính. 2 trong 3 trường hợp này đều được sinh thiết < 6 mẫu. Độ nhạy và độ đặc hiệu của phương pháp trên toàn bộ 84 bệnh nhân lẩn lượt là $93,8 \%$ và $82,8 \%$, giá trị dự đoán dương 
tính là $88.4 \%$, giá trị dự đoán âm tính 90.6\%. Trên 62 bệnh nhân được sinh thiết 10 điểm, xét nghiệm có độ nhạy là $96,9 \%$ và độ đặc hiệu là $86,2 \%$ (Bảng 3 )

Có 28 BN (33,3\%) gặp biến chứng trong và sau thủ thuật. Biến chứng thường gặp nhất là chảy máu qua hậu môn chiếm 17,8\% với mức độ ít, chỉ cần đặt meche cầm máu. Tiểu máu chiếm $14,2 \%$ với biểu hiện tiểu màu hồng nhạt. Có một $\mathrm{BN}$ có biểu hiện nhiễm trùng tầng sinh môn, và một bệnh nhân sốt nhẹ (dao động $37,5-38,5^{\circ} \mathrm{C}$ ).

Báng 3: So sánh kêt quả STTTL với kêt quả GPB sau mổ

\begin{tabular}{|c|c|c|c|c|}
\hline \multirow{2}{*}{} & \multirow{2}{*}{ Kết quả } & \multirow{2}{*}{$\mathbf{n}$} & \multicolumn{2}{|c|}{ Kết quả GPB } \\
\cline { 3 - 5 } & & & UT & Không UT \\
\hline Sinh thiết & $(+)$ & 52 & 46 & 6 \\
\cline { 2 - 5 } qua siêu âm & $(-)$ & 32 & 3 & 29 \\
\cline { 2 - 5 } trực tràng & Tống & 84 & 49 & 35 \\
\hline \multirow{2}{*}{$\begin{array}{c}\text { Sinh thiết } \\
10 \text { mẫu }\end{array}$} & $(+)$ & 36 & 32 & 4 \\
\cline { 2 - 5 } & $(-)$ & 26 & 1 & 25 \\
\cline { 2 - 5 } & Tổng & $\mathbf{6 2}$ & $\mathbf{3 3}$ & $\mathbf{2 9}$ \\
\hline
\end{tabular}

\section{BÀN LUÂNN}

Các nghiển cứu cho thấy tuổi là một yếu tố quan trọng trong tầm soát bệnh UTTTL với tỷ lệ mắc UTTTL tăng dần theo tuổi, tỷ lệ này theo nghiên cứu của J.Stephen là $7 \%, 23 \%, 39 \%$, $44 \%, 65 \%$ và $72 \%$ cho nam giới lần lượt theo các nhóm tuổi trên $30,40,50,60,70$ và 80 tuổi ${ }^{3}$. Trong nghiên cứu của chúng tôi, tuổi trung bình của các bệnh nhân là $72.1 \pm 8.7$, thấp nhất là 41 tuổi, cao nhất là 88 tuổi.

Phần lớn $\mathrm{BN}$ đến khám với các triệu chứng, hội chứng rối loạn tiểu tiện tắc nghẽn $(92,8 \%)$, tỷ lệ bí tiểu phải đặt sonde niệu đạo hoặc dẫn lưu bàng quang là $22,6 \%$. Có $36,9 \%$ BN có hội chứng kích thích đường tiết niệu dưới là tiểu rắt, tiểu đêm. Đây là những triệu chứng gây suy giảm chất lượng sống của bệnh nhân rất nhiêu do gây mất ngủ, và rối loạn sinh hoạt. Kết quả này phù hợp với các nghiên cứ trước đó của các tác giả Lê Ngọc Bằng và Khoury 4,5

Thăm khám tuyến tiền liệt qua trực tràng là một động tác rất quan trọng, nhất là ở những cơ sở chưa thực hiện được sinh thiết tuyến tiền liệt. Trong nghiên cứu của chúng tôi, thăm trực tràng phát hiện thấy có đến $44 \% B N$ có dấu hiệu nghi ngờ ung thư, với nhân rắn, mất ranh giới giữa 2 thùy sau. Kết quả thăm trực tràng của chúng tôi có độ nhạy là $58 \%$ và độ đặc hiệu là $62,5 \%$. So sánh với nghiên cứu của Lề Ngọc Bằng trên 53 BN có độ nhạy là $78,3 \%$ và độ đặc hiệu là $70 \%{ }^{4}$. Cũng theo Joe Philip sàng lọc trên 408 BN có độ nhạy là $61,2 \%$ và độ đặc hiệu là $59,8 \%{ }^{6}$. Kết quả nghiên cứu của chúng tôi tương đồng với kết quả của Joe Philip và thấp hơn kêt quả của Lê Ngọc Bằng có thể do đa số $\mathrm{BN}$ trong nghiên cứu của Lê Ngọc Bằng ở giai đoạn muộn ${ }^{4}$.

Kết quả siêu âm ổ bụng phát hiện được $27,3 \%$ BN có dấu hiệu nghi ngờ UTTTL, độ nhạy là $36,6 \%$ và độ đặc hiệu là $87,5 \%$. Trong khi đó siêu âm trực tràng phát hiện được 41,6\% BN có dấu hiệu nghi ngờ ung thư, với độ nhạy và độ đặc hiệu lần lượt là $61,5 \%$ và $90,6 \%$. Như vậy, khả nẳng phát hiện dấu hiệu nghi ngờ UTTTL trên siêu âm trực tràng là cao hơn hẳn siêu âm ổ bụng. Điều này khẳng định ưu thế của siêu âm trực tràng so với siêu âm ổ bụng trong chẩn đoán bệnh UTTTL. Đồng thời siêu âm trực tràng có ưu điểm lớn mà siêu âm ổ bụng không có được là định hướng cho sinh thiết làm tăng khả năng chẩn đoán UTTTL và đánh giá được mức độ xâm lấn của UTTTL tới các tạng vùng tiểu khung: cổ bàng quang, túi tinh, trực tràng.

Trong nghiên cứu của chúng tôi, PSA của nhóm BN sinh thiết (+) là 125,7 $213,2(\mathrm{ng} / \mathrm{ml})$. PSA của nhóm BN sinh thiết (-) là 42,4 $\pm 32,2$ $(\mathrm{ng} / \mathrm{ml})$. Sự tăng cao PSA của nhóm BN ung thư lớn hơn hẳn nhóm $\mathrm{BN}$ không ung thư với mức ý nghĩa $p=0,001$. Tỷ lệ sinh thiết dương tính ở các nhóm có $[P S A] \geq 10 \mathrm{ng} / \mathrm{ml}$, từ $50-100 \mathrm{ng} / \mathrm{ml}$ và $[\mathrm{PSA}]>100 \mathrm{ng} / \mathrm{ml}$ lần lượt là $65,3 \%, 70 \%$ và $93,9 \%$. Các kết quả này phù hợp với các nghiên cứu trước đó ${ }^{4,5}$ và một lần nữa khẳng định vai trò cửa PSA trong phát hiện sớm ung thư và hướng dẫn chỉ định sinh thiết tuyến tiền liệt.

Trong nghiên cứu này chúng tôi thực hiện phương pháp sinh thiết 10 mẫu là một phương pháp hiện được áp dụng rộng rãi trên thế giới. Trong qua trình thực hiện sinh thiết một số $B N$ (22 BN) không thực hiện được đủ 10 mẫu vì BN đau hoặc chảy máu trực tràng, tuy nhiên mẫu bệnh phẩm thu được vẫn đảm bảo để xác định tế bào và mô bệnh học. Có 52 bệnh nhân có kết quả sinh thiết dương tính, độ nhạy và độ đặc hiệu của phương pháp là $93.8 \%$ và $82,8 \%$. So sánh với các nghiên cứu khác sử dụng phương pháp sinh thiết tuyến tiền liệt 6 điểm, như theo nghiên cứu của Terris $\mathrm{MK}$, độ nhạy là $60 \%$ và độ đặc hiệu là $100 \%{ }^{7}$, còn của Eptein JI có độ nhạy là $71,9 \%$ và độ đặc hiệu từ $95,8 \%$ đến $97,1 \%{ }^{8}$, có thể thây rằng kết quả sinh thiết của chúng tôi chính xác hơn nhiêu. Bên cạnh đó, khi so sánh kết quả ở nhóm STTTL 10 mẫu, kết quả của chúng tôi thậm chí còn chính xác hơn với độ nhạy là $96,9 \%$ và độ đặc hiệu là $86,2 \%$. Từ đó có thể khẳng định rằng STTTL dưới hướng dẫn của $\mathrm{SA}$ qua trực tràng rất có giá trị trong chẩn 


\section{đoán UTTTL.}

Trong tổng số 84 BN chúng tôi sinh thiết, có $28 \mathrm{BN}$ gặp biến chứng trong và sau thủ thuật $(33,3 \%)$, chảy máu hậu môn $(17,8 \%)$, tiểu máu (14,2\%), sốt (1 trường hợp), có 1 bệnh nhân gặp nhiểm khuẩn tầng sinh môn, không gặp các biến chứng xuất tinh ra máu. Tai biến gặp chủ yếu là chảy máu hậu môn ở mức độ nhẹ và chỉ cân đặt meche cầm máu và rút meche sau một ngày máu tự cầm không cần phải xử trí thêm. Các $B N$ tiểu máu sau sinh thiết, nước tiểu màu hồng, được theo dõi sát sau hai ngày thì tự cầm. BN có dâu hiệu đau tầng sinh môn hoặc sốt $(37,8$ $\left.38,5^{\circ} \mathrm{C}\right)$, được chúng tôi xử trí bằng kháng sinh tĩnh mạch, hạ sốt đường uống thì hết sốt và giảm đau sau một ngày. Có thể thấy ${ }_{\ell}$ các tai biến này đều ở mức đô nhe, có thể dế dàng khắc phục hoặc tự khỏi. Kết quả này phù hợp với các nghiên cứu trước $\mathrm{c}^{7,8}$, từ đó khẳng định tính an toàn của sinh thiết tuyến tiền liệt dưới hướng dẫn siêu âm qua trực tràng.

\section{KẾT LUẬN}

STTTL dưới hướng dẫn của siêu âm qua trực tràng là một thủ thuật có độ chính xác cao (độ nhạy và độ đặc hiệu là $93.8 \%$ và $82,8 \%$ ), đồng thời cũng khá an toàn, ít biến chứng với hâu hết các biến chứng đều ở mức độ nhẹ.

\section{TÀI LIÊU THAM KHẢO}

1. Sung $H$, Ferlay $J$, Siegel $R L$, Laversanne $M$, Soerjomataram I, Jemal A, Bray F. Global Cancer Statistics 2020: GLOBOCAN Estimates of Incidence and Mortality Worldwide for 36 Cancers in 185 Countries. CA Cancer J Clin. 2021 May;71(3):209-249. doi: 10.3322/caac.21660. Epub 2021 Feb 4. PMID: 33538338.

2. Bruyerre.F, O. Traxer (2005), "Prise en charge du cancer de la prostate". Annales d'Urologie. ( Vol 39/suppl.1, Pg 1-16).

3. J.Stephen Jone, MD (2008), "Definin the problem: From subclinical disease to clinically insignifcant prostate cancer". Prostate byopsy. Chapter 1, pp $16-17$.

4. Lê Ngoc Bằng (2005), "Vai trò cửa sinh thiết kết hợp với PSA và siêu âm trong chẩn đoán UTTTL" Đề tài thạc sĩ y học ngoại khoa.

5. Khoury.s (1998), "Lés stades du cancer de la prostate" (Pg167), " Diagnostic du cancer de la prostate"(Pg179). Urologie - Cancer de la prostate.

6. Joe Philip, Subhajit Dutta Joy and al (2005), "Is a Digital Rectal Examination Necessary in the Diagnosis and Clinical Staging of Early Prostate Cancer", BJU International, 95, Pg 969-971.

7. Terris M.K (1999), "Sensitivity and specificity of sextant biopsies in the detection of prostate cancer: preliminary report".Urology. Sep;54(3):486-9.

8. Epstein JI, Sanderson H, Carter HB, Schafstein DO (2005)."Utility of saturation biopsy to predict insignificant cancer at radical prostatectomy". Urology. Aug; 66(2):356-60.

\title{
ĐÁNH GIÁ KẾT QUẢ BƯớC ĐẦU ĐIỀU TRI UNG THƯ BIỂU MÔ TẾ BÀO GAN BẰNG PHƯƠNG PHÁP NÚT MẠCH SỬ DƯNG CỒN TUYÊTT ĐỐI VÀ LIPIODOL
}

\author{
Nguyễn Duy Thịnh', Bùi Văn Giang,3, Phạm Thế Anh ${ }^{4}$,
} Vũ Lê Minh ${ }^{3}$, Nguyễn Quang Toàn ${ }^{3}$,

\section{TÓM TẮT}

Mục tiêu: Nghiên cứu nhằm đánh giá kết quả điều trị ung thư biểu mô tế bào gan bằng phương pháp nút mạch sử dụng cồn tuyệt đối và lipiodol. Đối tượng và phương pháp: Nghiển cứu được thực hiện trên 33 bệnh nhân ung thư biểu mô tế bào gan được nút mạch bắng côn tuyệt đối và lipiodol tại bệnh viện $\mathrm{K}$ cơ sở

\footnotetext{
${ }^{1}$ Bênh viện Thanh Nhàn

2Trường Đại hoc Y Hà Nội

${ }^{3}$ Trung tâm Chẩn đoán hình ảnh, Bệnh viện $K$ cơ sở Tân Triều

${ }^{4}$ Trung tâm Gan-Mật-Tưy, bệnh viện K cơ sở Tân Triều

Chịu trách nhiệm chính: Nguyễn Duy Thịnh

Email: saithanhvagabond2008@gmail.com

Ngày nhận bài: 4.6.2021

Ngày phản biên khoa hoc: 29.7.2021

Ngày duyệt bài: 6.8 .2021
}

Tân Triều từ tháng 03/2020 đến tháng 06/2021. Tiến hành tính và so sánh tỳ lệ đáp ứng điều trị sau can thiệp 01 và 03 tháng giữa 2 nhóm u có kích thước $\leq$ $10 \mathrm{~cm}$ và $>10 \mathrm{~cm}$, nhóm can thiệp sử dụng $E: L ~ 1: 1$ và $1: 2$. Theo dõi sư thay đổi nồng đô aFP sau can thiêp 01 tháng và 03 tháng. Kết quả: Tỷ lệ đáp ứng điều trị nhóm u có kích thước $\leq 10 \mathrm{~cm}$ cao hơn nhóm kích thước $u>10 \mathrm{~cm}(p<0,005)$, nhóm có tỷ lệ $E: L 1: 1$ cao hơn nhóm $E: L 1: 2(p<0,005)$. Nồng độ aFP giảm dân sau can thiệp 01 tháng và 03 tháng $(p<0,001)$. Kết luận: Điều trị UTBMTBG bằng TAELE là một phương pháp an toàn và hiệu quả cần được nghiên cứu thêm để đánh giá đầy đủ.

Tư khóa: Ung thư biểu mô tế bào gan, TAELE.

\section{SUMMARY \\ ASSESSMENT OF INITINAL TREATMENT \\ RESULTS HEPATOCELLULAR CARCINOMA BY METHOD EMBOLIZATION USING}

